\title{
From migration to mobility
}

\author{
By many accounts, climate change is already driving human migration, but fresh thinking about the consequences \\ of increasingly stringent borders, the intervening effects of global and local policy and how best to characterize \\ human adaptive responses is needed to properly understand whether a crisis is on the horizon.
}

T here is no question that climate change will impact human migration. The potential triggers are many: sealevel change leading to coastal flooding, drought destroying agricultural livelihoods, extreme heat threatening human health. By 2050, estimates for the expected number of environmental migrants are between 25 million and 1 billion. These numbers are, of course, uncertain and debated. But the idea of masses teeming from storm-ravaged and drought-stricken land is probably wrong, or at most only one small aspect of what is likely to unfold. When, where and how people will be forced to move as a consequence of climate change remains elusive, as are definitions about what it means to be a climate migrant and how best to govern the problem. In this issue and an accompanying online collection (www. nature.com/collections/climate-migration), we explore many of these questions and what needs to be done to improve our understanding of the complex, multi-faceted interaction between climate change and human migration.

Everything from livelihoods to identity is affected by the environments in which we live, so it makes sense that environmental change would influence decisions to stay or go. Although not always explicit, classic migration theory is generally compatible with the idea that environmental factors matter, and there is a rapidly growing literature contributing to migration-environment theory. There are a few things we know at this point: (1) migration is a fundamental strategy for addressing household risk arising from the environment; (2) environmental factors interact with broader sociopolitical histories; and (3) the migration-environment association is shaped by social networks (L. M. Hunter et al., Annu. Rev. Sociol. 41, 377-397; 2015).

Notably, what we know about environmental migration is that a lot of non-environmental factors matter. An improved understanding of the physical processes alone is important, but as Wrathall et al. explain in this issue, exposure to

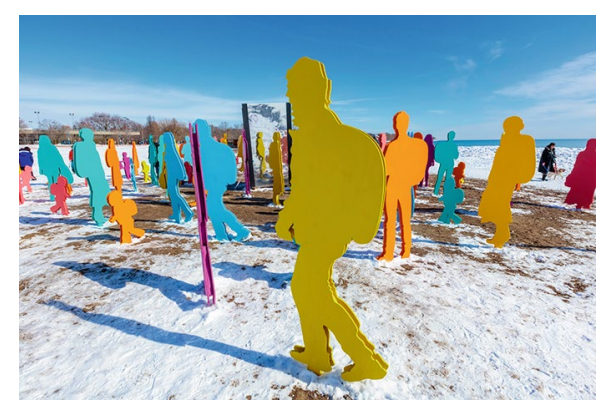

Credit: Bill Brooks / Alamy Stock Photo

sea-level change is driven concurrently by global policy decisions determining future greenhouse gas emissions and local policies at the migrants' point of origin. To get a better handle on the space of potential outcomes, they advocate for improved modelling that prioritizes scenarios consistent with global objectives (the Paris Agreement goals), allows for consideration of local and national policies, and focuses first on predicting migration through 2050.

Migration decisions are further impacted by policies at potential destinations. Although exposure to climate risks is sure to be broad, whether climate change leads to a larger number of migrants is at least in part conditional on whether those at risk have somewhere to go. In a Perspective in this issue, Robert McLeman discusses how restrictive policies, criminalization of asylum seekers and securitization of immigration is increasingly closing the door to international migration. With nowhere to go, the vulnerable may be forced to stay put and forgo using migration as an adaptation strategy.

For example, in a News \& Views article in this issue, Cristina Cattaneo explores a recent study looking at the role of migrant networks in shaping disaster-induced migration to the United States. This new research shows that prior migrants amplify international migration flows in the aftermath of hurricanes. Although the results are consistent with migration being used as an adaptive strategy, they also suggest that migration may not be a pathway available to those who need it the most. For reasons such as this, McLeman advocates for more explicit application of the United Nations Global Compact for Safe, Orderly and Regular Migration (A/RES/73/195, 2018) to facilitate international migration in response to climate hazards.

Perhaps our inability to wrap our heads around the problem at the policy level arises because we have completely mischaracterized the problem that needs to be solved. In a Comment in this issue, Ingrid Boas and colleagues argue that framing climate migration as an impending security risk for the developed world hinders efforts to advance knowledge and policy that properly account for the complex nature of the problem. They argue for a reorientation of research and funding to focus on the full range of mobilities likely to result from climate change.

Environmental migration occurs both between and within countries; it may be temporary or permanent; it may follow existing routes or forge new ones. The ultimate challenge is to find solutions to reduce the climate risks that lie ahead. The need to rethink migration in terms of mobilities is pressing, especially in light of the difficulties in establishing a super-framework for climate migration. For many, the question is not whether or when they will be impacted, but how they should retreat now, and what are the costs of doing so. A News Feature in this issue highlights these very challenges for Newtok, Alaska and Isle de Jean Charles, Louisiana in the United States, both of which are in search of ways to relocate their threatened coastline communities away from the sea. Retreat may be inevitable. And, although this is unlikely to include refugees on foot crossing international borders, these residents are very much climate migrants. It is for this reason that new models, new conceptions or new policies are needed to understand the full space of human responses to climate change.

Published online: 26 November 2019 https://doi.org/10.1038/s41558-019-0657-8 